\title{
西北地区水资源与食物安全可持续发展研究

\author{
王玉宝，刘显，史利洁，上官周平，吴普特，山仑，赵西宁
} \\ （西北农林科技大学，陕西杨凌 712100）
}

摘要：西北地区光热土资源丰富, 区域食物安全的可持续发展主要受限于其有限的水资源。本文以水足迹和虚拟水为分析工 具, 评估了西北地区作物生产用水效率、水资源压力和作物虚拟水输出情况。基于国际化绿色化背景, 以及西北地区粮食生 产及农业用水的预测结果, 提出逐步减少区域农业用水总量, 优化调整作物种植结构和实施丝路经济带虚拟水工程, 以期为 区域水资源合理利用和食物安全战略的制定提供参考。

关键词: 西北地区; 食物安全; 水资源; 可持续发展

中图分类号: TV21 文献标识码：A

\section{Sustainable Development of Water Resources and Food Security in Northwest China}

\author{
Wang Yubao, Liu Xian, Shi Lijie, Shangguan Zhouping, Wu Pute, Shan Lun, Zhao Xining
}

(Northwest A\&F University, Yangling 712100, Shaanxi, China)

\begin{abstract}
Northwest China has abundant light, heat, and land resources, but limited water resources which has restricted the sustainable development of food security in this region. Water-use efficiency in crop production, water resources stress, and virtual water output of crops in Northwest China are evaluated using water footprint and virtual water as analysis tools. Grain production and agricultural water use in Northwest China are predicted. Furthermore, policy suggestions are proposed to guarantee the sustainable development of water resources and food security in Northwest China, including gradually reducing the scale of agricultural water use in this region, optimizing the crop planting structure, and implementing a virtual water project along the Silk Road Economic Belt. This study is hoped to provide a reference for the rational utilization of regional water resources and the formulation of food security strategies.
\end{abstract}

Keywords: Northwest China; food security; water resource; sustainable development

\section{一、前言}

近年来, 西北地区食物生产取得了较大进步, 当前粮食、蔬菜和瓜果等食物人均产量均已超过 全国水平。但是, 西北地区水资源极度缺乏, 大
量的食物生产给区域脆弱的生态环境带来了巨大灾 难 [1]。人口的持续增长, 动物性食物消费比例的 提高, 气候变化引起的蒸散增加等情况, 将进一步 加剧区域水资源危机。水资源已成为区域食物安全 可持续发展的瓶颈 [2]。但同时，西北地区农业用

收稿日期 : 2019-08-15; 修回日期 : 2019-09-08

通讯作者: 赵西宁, 西北农林科技大学研究员, 主要研究方向为农业高效用水; E-mail: xiningz@aliyun.com 资助项目：中国工程院咨询项目 “国际化绿色化背景下国家区域食物安全可持续发展战略研究” (2016-ZD-09)

本刊网址：www.engineering.org.cn/ch/journal/sscae 
水浪费严重，水分生产率低于全国平均水平。

伴随着中国南方经济的快速发展, 大量的耕地 被占用, 未来我国北方旱区仍将为粮食主产地区; 同时，因经济社会发展、城镇化建设和生态保护等 的需要, 未来西北地区的农业生产将面临产量有所 增加而用水量不增加甚至负增长的挑战。此外, 气 候变化和极端天气的增加也给未来西北地区粮食安 全生产带来潜在威胁 [3]。

本文立足国际化绿色化背景，结合中国现代农 业发展的整体战略布局, 围绕西北地区农业生产结 构及其宏观布局, 通过分析西北地区主要粮、经作 物生产水足迹，农业生产水资源压力，区域食物虚 拟水流动, 研究西北地区农业用水与食物安全的关 系, 提出改善西北地区农业用水状况, 促进区域农 业生产可持续发展和食物安全的措施。

\section{二、西北地区水资源现状及农业用水评价}

\section{（一）西北地区水资源现状}

西北地区幅员辽阔，光热土资源丰富，国土面 积约占全国的 $41.4 \%$, 是中国重要的粮食生产后备 基地，以约占全国 10\% 的水资源量和 $15 \%$ 的粮食种 植面积生产全国 $12 \%$ 的粮食。西北地区的粮食生产 对确保我国粮食安全具有重要意义。但西北地区水 资源缺乏, 是我国最为干旱的地区, 降水稀少、蒸
发强烈。降水集中发生在 6-9 月份，多以大雨或暴 雨形式出现，水土流失严重。亩均水资源量不到全 国平均水平的一半，且水土资源在空间上极不匹配， 而降水稀少又使得西北地区农业生产高度依赖灌 溉。由于经济发展相对滞后, 长期以来, 西北地区 农牧业发展耗用了大量水资源，水资源开发利用率 高, 部分流域如石羊河流域水资源开发利用率超过 了 $100 \%$, 引起了一系列生态问题 $[1,4]$ 。此外，水 源枯竭正进一步恶化水资源圆乏的现状。冰川退缩、 雪线上升，导致地表水径流减少 [5]。在资源型缺 水加剧的同时, 西北地区的水质也在逐步恶化 [6]。

\section{（二）西北地区农业用水评价}

农业在西北地区的经济发展中具有重要地位, 农田灌溉用水占总用水量接近 70\%, 部分地区农业 用水比例达到了 $90 \%$ 以上。西北地区农田灌溉用 水量占区域总用水量的百分比高于全国值, 其中新 疆、宁夏和甘肃尤为突出。近年来, 随着其他行业 对农业用水的挤占, 农业灌溉用水量比例在逐步下 降（见表 1)。

以水足迹为工具, 分析西北地区 9 种主要作物 的生产水足迹, 以量化西北地区农业对降水（绿水） 和灌溉水 (蓝水) 的利用情况, 并进一步分析作物 生产水足迹的时空演变特征。作物生产水足迹是区 域生产单位作物产品所消耗的水资源量（包括蓝水

表 1 西北地区农业灌溉总体情况

\begin{tabular}{lcccccccccc}
\hline 项目 & 时间/年 & 内蒙古 & 宁夏 & 甘肃 & 青海 & 陕西 & 山西 & 新疆 & 西北 & 中国 \\
\hline 灌溉面积占作物 & 2000 & 40 & 39 & 25 & 38 & 29 & 27 & 91 & 41 \\
总播种面积比例 $/ \%$ & 2005 & 43 & 45 & 28 & 37 & 30 & 29 & 86 & 43 & 35 \\
& 2010 & 43 & 37 & 26 & 48 & 31 & 34 & 85 & 45 & 38 \\
& 2015 & 41 & 39 & 31 & 33 & 29 & 39 & 84 & 45 & 40 \\
& 2016 & 40 & 40 & 31 & 36 & 29 & 40 & 85 & 46 & 40 \\
& 2000 & 87 & 92 & 80 & 72 & 73 & 65 & 95 & 87 & 62 \\
农田灌溉用水占 & 2005 & 82 & 93 & 79 & 69 & 66 & 55 & 91 & 84 \\
总用水量比例 $/ \%$ & 2010 & 70 & 92 & 79 & 60 & 59 & 56 & 91 & 80 & 57 \\
& 2015 & 66 & 88 & 81 & 51 & 54 & 61 & 94 & 81 & 63 \\
& 2016 & 73 & 87 & 80 & 75 & 53 & 62 & 94 & 83 & 62 \\
& 2000 & 446 & 1213 & 619 & 644 & 303 & 210 & 829 & 609 & 479 \\
亩均灌溉用水量 $/ \mathrm{m}^{3}$ & 2005 & 378 & 979 & 559 & 616 & 287 & 209 & 753 & 540 & 448 \\
& 2010 & 362 & 981 & 559 & 597 & 305 & 217 & 673 & 528 & 421 \\
& 2015 & 327 & 705 & 497 & 565 & 300 & 186 & 617 & 457 & 394 \\
& 2016 & 305 & 636 & 487 & 565 & 312 & 188 & 617 & 444 & 380
\end{tabular}


和绿水)。

如图 1 所示, 西北地区综合粮食作物生产水足 迹均呈波动下降趋势, 作物生产蓝水足迹占作物生 产水足迹的比例也多呈波动下降趋势, 但下降幅度 相对较小。

从西北整体来看, 2010 年以前, 西北地区综合 粮食作物生产水足迹均大于全国平均水平, 近年来 西北地区综合粮食作物生产水足迹稍低于全国平均 水平。在研究时段内, 西北地区蓝水生产足迹始终 高于全国平均水平, 但差距有明显的减小。绿水生 产足迹始终低于全国平均水平, 且两者间的差距有 增大的趋势。表明西北地区粮食生产消耗了更多的 蓝水资源。

对于西北地区 9 种作物生产水足迹及其组成, 同一区域不同作物之间差异显著, 即存在绝对比较 优势; 同一作物不同区域之间差异也显著, 即存在
相对比较优势。

虚拟水是指生产商品和服务中所需要的水资源 量。当一个地区的某种作物产品生产不能满足或超 过本地区的需求时, 就可能产生区域间该种作物产 品的贸易, 随之也产生了虚拟水在区域间的流动。 西北地区与中国其他区域间的粮食贸易过程中, 主 要是粮食输出的角色, 且呈波动上升趋势, 2016 年 西北地区输出粮食量超过 $1.0 \times 10^{7} \mathrm{t}$, 输出的经济作 物量超过 $2.9 \times 10^{7} \mathrm{t}$ 。伴随着作物产品的贸易, 2008 年之后, 西北地区每年向外输出的虚拟水量均超过 $1.0 \times 10^{10} \mathrm{~m}^{3}, 2016$ 年更是高达 $2.527 \times 10^{10} \mathrm{~m}^{3}$ (见 表 2)。

\section{三、西北地区水资源压力评价}

以水资源开发利用率来衡量区域水资源压力,

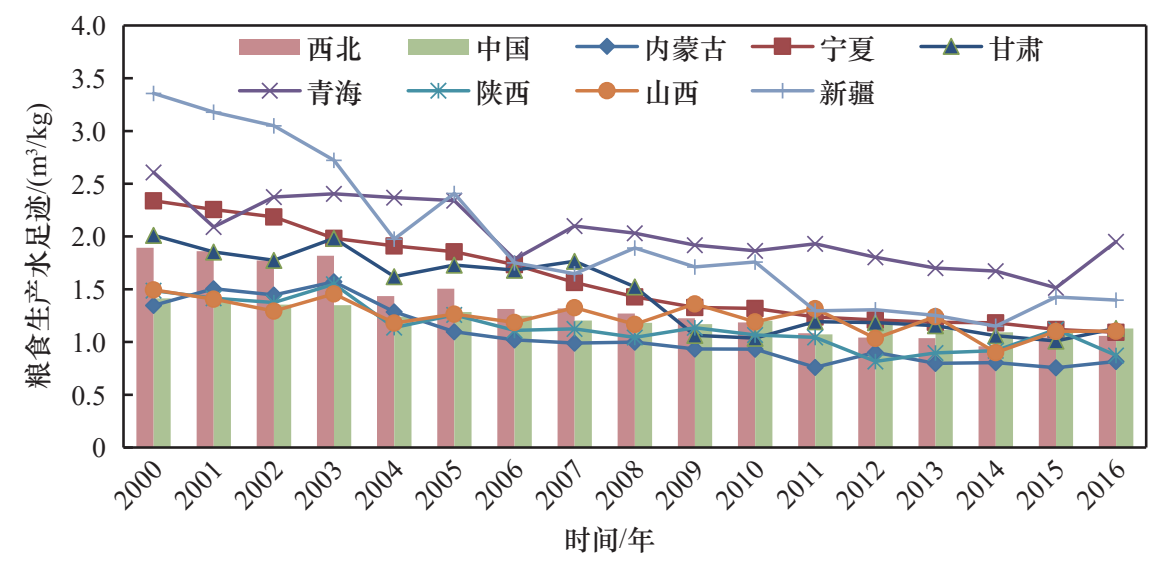

(a)

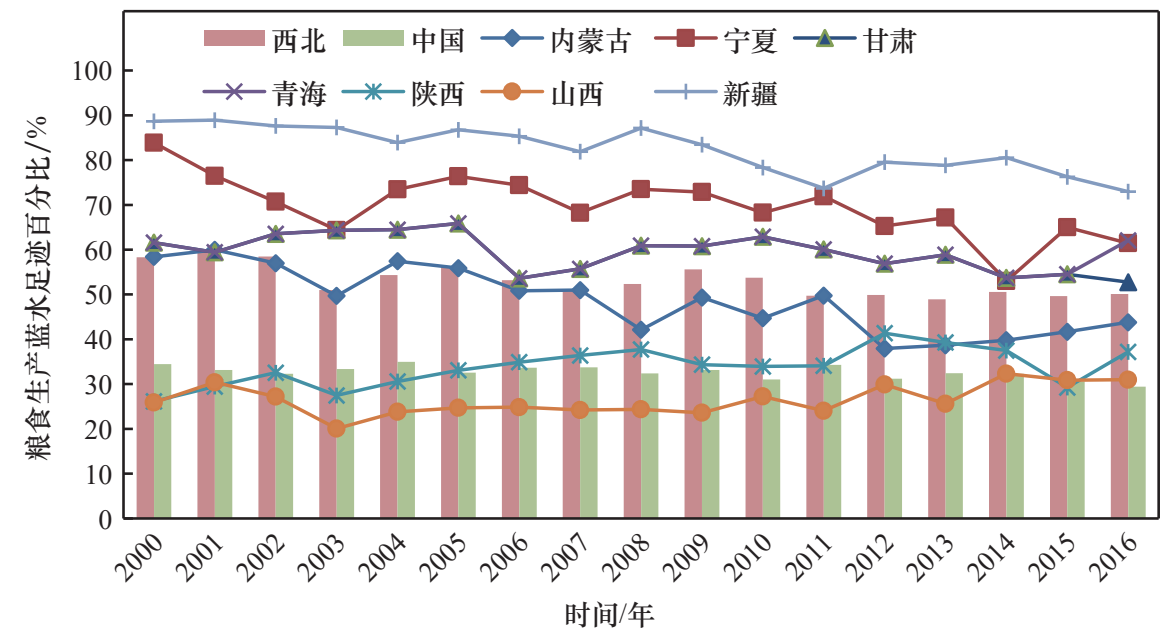

(b)

图 1 西北地区综合粮食作物生产水足迹及其组成演变趋势（2000-2016） 
表 2 西北地区与国内其他地区作物贸易产生的虚拟水贸易量

$\times 10^{8} \mathrm{~m}^{3}$

\begin{tabular}{|c|c|c|c|c|c|c|c|c|c|c|c|c|}
\hline 时间 / 年 & $\begin{array}{l}\text { 稻谷 } \\
\end{array}$ & 小麦 & 玉米 & 豆类 & 薯类 & 粮食 & 棉花 & 油料 & 蔬菜 & 水果 & 经济作物 & 总量 \\
\hline 2000 & -255.3 & 111.7 & 109.4 & 16.4 & 2.3 & -15.5 & 46.2 & -4.7 & -53.9 & 42.7 & 30.3 & 14.8 \\
\hline 2001 & -235.2 & 114.1 & 102.4 & 8.4 & 0.9 & -9.5 & 43.6 & -27.1 & -68.4 & 34.2 & -17.8 & -27.3 \\
\hline 2002 & -227.5 & 130.1 & 127.5 & 18.0 & 2.9 & 51.0 & 43.4 & -8.4 & -65.9 & 41.2 & 10.3 & 61.3 \\
\hline 2003 & -214.1 & 107.6 & 169.1 & 2.0 & 4.7 & 69.3 & 46.2 & -3.0 & -58.2 & 18.1 & 3.1 & 72.4 \\
\hline 2004 & -227.7 & 82.3 & 147.0 & 14.1 & 3.6 & 19.3 & 37.9 & -11.8 & -50.7 & 18.6 & -6.0 & 13.3 \\
\hline 2005 & -228.7 & 82.4 & 154.5 & 23.6 & 2.4 & 34.2 & 48.7 & -10.6 & -52.8 & 25.3 & 10.7 & 44.9 \\
\hline 2006 & -224.6 & 58.1 & 123.5 & 23.9 & 5.5 & -13.7 & 41.0 & -2.2 & -33.2 & 34.4 & 40.0 & 26.3 \\
\hline 2007 & -225.2 & 33.3 & 143.7 & 33.8 & 5.1 & -9.4 & 60.5 & -17.2 & -25.0 & 39.8 & 58.2 & 48.8 \\
\hline 2008 & -227.9 & 47.7 & 158.2 & 21.4 & 5.6 & 5.1 & 65.7 & 0.2 & -30.8 & 59.4 & 94.6 & 99.7 \\
\hline 2009 & -230.6 & 71.4 & 153.0 & 18.6 & 2.9 & 15.3 & 47.9 & -0.8 & -17.4 & 69.6 & 99.4 & 114.6 \\
\hline 2010 & -238.1 & 70.9 & 165.2 & 24.0 & 2.9 & 25.1 & 49.0 & 1.5 & -13.6 & 74.0 & 110.9 & 136.0 \\
\hline 2011 & -223.9 & 54.9 & 179.6 & 22.8 & 4.2 & 37.7 & 45.4 & 0.9 & -8.3 & 72.2 & 110.2 & 147.8 \\
\hline 2012 & -250.2 & 58.3 & 194.6 & 26.2 & 4.1 & 32.9 & 55.6 & 0.2 & -12.8 & 74.9 & 117.8 & 150.7 \\
\hline 2013 & -239.7 & 41.7 & 232.2 & 21.2 & 4.5 & 59.8 & 54.6 & 0.6 & -11.9 & 84.1 & 127.4 & 187.2 \\
\hline 2014 & -238.8 & 45.0 & 219.1 & 7.8 & 3.8 & 36.9 & 51.8 & 2.6 & -16.6 & 91.4 & 129.2 & 166.1 \\
\hline 2015 & -229.8 & 67.2 & 247.5 & 10.3 & 3.2 & 98.5 & 62.1 & 7.9 & 5.6 & 110.2 & 185.9 & 284.4 \\
\hline 2016 & -236.5 & 73.4 & 263.9 & 12.5 & 4.5 & 124.2 & 63.3 & 0.7 & -0.7 & 120.8 & 128.5 & 252.7 \\
\hline
\end{tabular}

注: 负号表示虚拟水流入西北地区; 反之为虚拟水流出西北地区。

当水资源开发利用率小于 $10 \%$ 时为低水资源压力; 当水资源开发利用率大于 $10 \%$ 、小于 $20 \%$ 时为中 低水资源压力; 当水资源开发利用率大于 $20 \%$ 、小 于 $40 \%$ 时为中高水资源压力; 当水资源开发利用 率大于 $40 \%$ 时为高水资源压力。

西北地区水资源压力在中高水资源压力与高水 资源压力界线浮动, 而全国水资源压力在中低水资 源压力和中高水资源压力界限浮动, 说明西北地区 面临的水资源短缺已非常严峻（见表 3 )。

\section{四、西北地区粮食生产及农业用水预测}

借助线性回归和灰色系统模型中的 $\operatorname{GM}(1,1)$ 模型对西北地区粮食单产、粮食产量、作物生产 水足迹和降水变化情况进行预测。按照预测的粮 食单产和粮食产量, 未来西北地区粮食的种植面 积有一定增加, 即便按粮食种植面积不变进行保 守估计, 未来西北地区人均粮食产量仍高于全国 均值, 即西北地区作为粮食输出区的现状在未来 仍然不会改变。未来西北地区降水会有小幅度增 加, 但考虑到未来气候变化的温度升高会造成蒸 散增大, 需要合理控制西北地区的耕地面积和作 物种植结构并适当发展旱作农业, 以确保未来作
物蓝水足迹能有所下降，农业用水压力不会增大 (见表 4)。

\section{五、政策建议}

\section{（一）逐步减少农业用水总量}

依据食物绿色化要求，应考虑土地资源储备、 耕地质量保育、水资源压力和生态承载力等因素的 综合影响, 对西北地区进行合理开发和保护。西北 地区是我国最为干旱的地区, 也是我国水土流失最 为严重的地区，其生态系统又极度依赖于水资源系 统，而西北地区水资源开发利用率超过了 $40 \%$ ，属 于高水资源压力，农业用水占总用水量比例高，因 此应逐步减小农业用水规模, 促进区域可持续发展。

\section{（二）优化调整作物种植结构}

在确保口粮供给的前提下，依据同一区域不同 作物间的绝对比较优势和同一作物不同区域间的相 对比较优势, 调整作物种植结构, 减少高耗水作物 面积, 增加作物降水利用比例, 提高用水效率和用 水效益，减少区域水资源使用量，缓解区域水资源 压力。西北地区应增加饲料作物种植比例, 改变当 前的粮经二元作物结构为粮经饲三元作物结构。 
表 3 西北和中国农业用水及对水资源压力的贡献率

$\%$

\begin{tabular}{|c|c|c|c|c|}
\hline \multirow{2}{*}{ 时间 / 年 } & \multicolumn{2}{|c|}{ 总用水量 / 水资源总量 } & \multicolumn{2}{|c|}{ 灌溉用水量 / 总用水量 } \\
\hline & 西北 & 中国 & 西北 & 中国 \\
\hline 2000 & 42.4 & 19.8 & 86.9 & 68.8 \\
\hline 2001 & 39.9 & 20.7 & 83.8 & 68.7 \\
\hline 2002 & 40.8 & 19.5 & 88.2 & 68.0 \\
\hline 2003 & 33.2 & 19.4 & 84.7 & 64.5 \\
\hline 2004 & 40.8 & 23.0 & 74.1 & 64.6 \\
\hline 2005 & 33.0 & 20.1 & 84.1 & 63.6 \\
\hline 2006 & 42.6 & 22.9 & 70.3 & 63.2 \\
\hline 2007 & 41.4 & 23.0 & 70.3 & 61.9 \\
\hline 2008 & 43.3 & 21.5 & 81.5 & 62.0 \\
\hline 2009 & 38.6 & 24.7 & 82.0 & 62.4 \\
\hline 2010 & 35.0 & 19.5 & 80.6 & 61.3 \\
\hline 2011 & 36.2 & 26.3 & 68.3 & 61.3 \\
\hline 2012 & 37.1 & 20.8 & 69.9 & 63.3 \\
\hline 2013 & 34.5 & 22.1 & 70.8 & 63.4 \\
\hline 2014 & 41.4 & 22.4 & 70.4 & 63.5 \\
\hline 2015 & 42.7 & 21.8 & 80.7 & 63.1 \\
\hline 2016 & 41.7 & 18.6 & 82.9 & 62.4 \\
\hline 平均 & 39.1 & 21.5 & 78.2 & 63.9 \\
\hline
\end{tabular}

表 4 西北地区人口、粮食单产、粮食产量、作物蓝水足迹和降水量预测值

\begin{tabular}{|c|c|c|c|c|c|}
\hline 时间 / 年 & 人口 $/ \times 10^{4}$ 人 & 粮食单产/ $\left(\mathrm{kg} / \mathrm{hm}^{2}\right)$ & 粮食产量 $/ \times 10^{4} \mathrm{t}$ & 作物蓝水足迹 $/ \times 10^{8} \mathrm{~m}^{3}$ & 降水量 $/ \mathrm{m}$ \\
\hline 2017 & 16371 & 4717 & 8886 & 588 & 0.310 \\
\hline 2018 & 16470 & 4917 & 9180 & 584 & 0.311 \\
\hline 2019 & 16570 & 5019 & 9432 & 579 & 0.311 \\
\hline 2020 & 16670 & 5121 & 9684 & 575 & 0.312 \\
\hline 2021 & 16770 & 5223 & 9936 & 571 & 0.313 \\
\hline 2022 & 16869 & 5325 & 10187 & 567 & 0.314 \\
\hline 2023 & 16969 & 5427 & 10439 & 563 & 0.315 \\
\hline 2024 & 17069 & 5529 & 10691 & 559 & 0.316 \\
\hline 2025 & 17168 & 5631 & 10943 & 555 & 0.317 \\
\hline 2026 & 17268 & 5734 & 11195 & 551 & 0.318 \\
\hline 2027 & 17368 & 5836 & 11447 & 547 & 0.319 \\
\hline 2028 & 17468 & 5938 & 11699 & 544 & 0.320 \\
\hline 2029 & 17567 & 6040 & 11951 & 540 & 0.321 \\
\hline 2030 & 17667 & 6142 & 12203 & 536 & 0.322 \\
\hline 2031 & 17767 & 6244 & 12455 & 532 & 0.323 \\
\hline 2032 & 17866 & 6346 & 12707 & 528 & 0.324 \\
\hline 2033 & 17966 & 6448 & 12958 & 525 & 0.325 \\
\hline 2034 & 18066 & 6550 & 13210 & 521 & 0.326 \\
\hline 2035 & 18165 & 6652 & 13462 & 517 & 0.327 \\
\hline
\end{tabular}

（三）实施丝路经济带虚拟水工程

我国人口持续增长，尤其全面放开二胎政策
会导致粮食消费量的增加, 到 2035 年还需要新增 $1.0 \times 10^{8} \mathrm{t}$ 粮食。耕地资源和水资源的限制, 以及我 
国居民对食物质量和结构多样性的要求, 已很难通 过发展国内生产来满足粮食持续增长的需求。长期 以来, 我国粮食主要进口国比较单一, 运输距离远, 给粮食安全带来巨大隐患。“一带一路”倡议的实施, 为中国粮食安全提供了新的契机。“一带一路”沿 线多是发展中国家, 各国都有发展农业合作、促进 农业转型升级的共同诉求。比较人均耕地资源和粮 食生产现状, 中亚五国 (哈萨克斯坦、乌兹别克斯 坦、吉尔吉斯斯坦、土库曼斯坦、塔吉克斯坦) 具 备打造成中国战略储备粮仓的潜力。

中亚五国与我国西北地区类似, 光热资源丰 富, 国土面积合计约为 $4 \times 10^{6} \mathrm{~km}^{2}$, 其中耕地面 积为 $3.241 \times 10^{7} \mathrm{hm}^{2}$, 相当于我国耕地面积总量 的 $1 / 4$, 草地面积为 $2.5 \times 10^{8} \mathrm{hm}^{2}$, 相当于我国的 3/4 [7 9]; 另有部分可耕地未被利用。年降水量为 160 700 mm, 人均水资源量均低于 $8000 \mathrm{~m}^{3}$, 但高 于我国西北地区人均水资源量 $2310 \mathrm{~m}^{3}$ 的水平。

中亚五国农业以种植业和畜牧业为主，每一农 业劳动力平均拥有 $5 \mathrm{hm}^{2}$ 耕地和 $39 \mathrm{hm}^{2}$ 草场。种植 业以粮食 (小麦、玉米和水稻)、油料和棉花这三 类土地密集型产品为主, 畜牧业以养羊、牛、马为 主。农业投入严重不足, 生产技术落后, 粮食单产 低、灌溉定额大, 用水效率低 [9]。

中亚五国与我国, 尤其是西北地区在农业领 域有较好的互补性和互利性, 具备很好的农业合作 潜力。中亚五国与我国西北地区毗邻, 边境线大于 $3000 \mathrm{~km}$, 有九个跨界同缘民族, 语言和风俗习惯 类似, 文化生活联系广泛 [9]。依靠这种地缘优势, 西北地区已经成为我国向西开放的前沿阵地, 成为 与中亚国家对外经济合作重要的承接地和聚合点。 此外欧亚大陆桥的贯通, 上海合作组织合作平台的 建立, 国家西部大开发、丝路经济带政策的实施为 西北地区食物贸易提供了战略机遇, 也为食物虚拟 水工程奠定了坚实的基础。

（1）提升中亚五国农业生产及用水水平。中亚 五国农业投入普遍不足, 农业机械发展相对滞后, 劳动力生产率低, 有巨大潜力可以挖掘。中亚五 国现有谷物播种面积为 $1.774 \times 10^{7} \mathrm{hm}^{2}$, 相当于我 国的 $19 \%$, 我国西北地区的 $234 \%$; 年谷物总产量 为 $2.9 \times 10^{7} \mathrm{t}$, 相当于我国的 $5 \%$, 我国西北地区的 $74 \%$; 单产为 $1635 \mathrm{~kg} / \mathrm{hm}^{2}$, 相当于我国的 $27 \%$, 我 国西北地区的 $32 \%$, 若其单产能提高到我国西北地
区水平，则年增产达 $6.164 \times 10^{7} \mathrm{t}$, 若其单产能提 高到我国平均水平, 则年增产达 $7.843 \times 10^{7} \mathrm{t}$, 接 近我国目前的粮食总进口量。农业节水灌溉面积较 少, 用水效率低下, 灌溉水利用效率不及我国西北 地区的 20\%, 故对农业节水灌溉技术具有极强的需 求; 而我国西北地区具有资金优势, 农业机械化率 和农业科技水平相比中亚国家较高, 如新疆在地膜 覆盖技术和膜下滴灌技术方面具有较成熟的经验和 较高的技术水平, 拥有自主研发的节水灌溉产品及 技术。因此, 丝路经济带食物虚拟水工程应首先加 强对中亚五国农业的技术与资金支持，在尽量不增 加其农业水资源利用量和耕地面积的前提下, 提升 其农业生产水平和用水水平进而提高粮食产量。

（2）优化调整我国西北地区、中亚五国产业结 构及种植结构。中亚五国降水主要集中在冬春季, 我国西北地区降水主要集中在 6-9 月, 因此中亚 五国小麦、油料作物的降水利用比例相对较高, 灌 溉水需求较少; 中亚五国草地资源丰富, 有利于发 展畜牧产业, 但由于食品加工业发展严重滞后, 畜 产品加工产品少。我国畜禽产业使用饲料粮较多, 需要耗用较多的水资源。因此, 应将我国西北地区 和中亚五国食物产业统筹考虑, 加强地区之间的协 调, 将水资源作为重点考虑因素, 优化调整我国西 北地区和中亚五国产业结构及种植结构, 使得各区 域建立起适水型的产业结构和种植结构。

(3) 发展我国西北地区与中亚五国食物虚拟水 贸易。进一步改善区域之间的交通设施, 完善双边 和多边贸易协调机制, 建立 “互联网+现代农业” 商业营销模式等, 为我国西北地区与中亚五国食物 虚拟水贸易的实施奠定基础。

\section{参考文献}

[1] 刘昌明, 王礼先, 夏军. 西北地区水资源配置生态环境建设和可 持续发展战略研究·生态环境卷: 西北地区生态环境建设区域 配置与生态环境需水量研究 [M]. 北京: 科学出版社, 2004.

Liu C M, Wang L X, Xia J. Study on the allocation of water resources, ecological environment construction and sustainable development strategy in Northwest China Ecological environment: Study on regional allocation of ecological environment construction and ecological environmental water demand in Northwest China [M]. Beijing: China Science Publishing \& Media Ltd (CSPM), 2004.

[2] 王浩, 秦大庸, 王建华, 等. 西北内陆干旱区水资源承载能力研 究 [J]. 自然资源学报, 2004, 19(2): 151-159.

Wang H, Qin D Y, Wang J H, et al. Study on carrying capacity of 
water resources in inland arid zone of Northwest China [J]. Journal of Natural Resources, 2004, 19(2): 151-159.

[3] 赵传燕, 程国栋, 邹松兵, 等. 西北地区自然植被净第一性生 产力的空间分布 [J]. 兰州大学学报(自然科学版), 2009, 45(1): 43-49.

Zhao C Y, Cheng G D, Zou S B. et al. Spatial distribution of net primary productivity of Natural vegetation in the Northwest China [J]. Journal of Lanzhou University (Natural Sciences Edition), 2009, 45(1): 43-49.

[4] 邓铭江. 中国西北“水三线”空间格局与水资源配置方略 [J]. 地 理学报, 2018, 71(7): 1189-1203.

Deng M J. "Three Water Lines" strategy: Its spatial patterns and effects on water resources allocation in Northwest China [J]. Acta Geographica Sinica, 2018, 71(7): 1189-1203.

[5] 陈亚宁, 杨青, 罗毅, 等. 西北干旱区水资源问题研究思考 [J]. 干 旱区地理, 2012, 35(1): 1-9.

Chen Y N, Yang Q, Luo Y, et al. Ponder on the issues of water resources in the arid region of Northwest China [J]. Arid Land Geography, 2012, 35(1): 1-9.

[6] 苏贤保, 李勋贵, 刘巨峰, 等. 基于综合权重法的西北典型区域 水资源脆弱性评价研究 [J]. 干旱区资源与环境, 2018, 32(3):
$112-118$.

Su X B, Li X G, Liu J F, et al. Vulnerability assessment of water resources in the northwest typical area based on comprehensive weighting method [J]. Journal of Arid Land Resources and Environment, 2018, 32(3): 112-118.

[7] 邹亚荣, 张增祥, 赵晓丽, 等. GIS支持下我国干旱区草地资源动 态分析 [J]. 环境科学研究, 2003, 16(1): 19-26.

Zou Y R, Zhang Z X, Zhao X L, et al. Analysis of grassland resource dynamics in China's arid region supported by GIS [J]. Research of Environmental Sciences, 2003, 16(1): 19-26.

[8] 方精云, 耿晓庆, 赵霞, 等. 我国草地面积有多大? [J]. 科学通报, 2018, 63(17): 1731-1739.

Fang J Y, Geng X Q, Zhao X, et al. How many areas of grasslands are there in China? [J]. Chinese Science Bulletin, 2018, 63(17): 1731-1739.

[9] 布娲单鸟·阿布拉. 中亚五国农业及与中国农业的互补性分析 [J]. 农业经济问题, 2008, 63(3): 104-109.

Buwajian Alabu. Analysis of the complementarity between agriculture of five central Asian Countries and that of China[J]. Agricultural Economic Problems, 2008, 63(3): 104-109. 